Andrii Ye. Vusatiuk, PhD student (construction)

ORCID ID 0000-0002-3096-3188,e-mail: avusatiuk@gmail.com

Gennadiy G. Fareniuk, Doctor Habilitat (construction), Director of the Institute

ORCID ID 0000-0002-5703-3976, e-mail: farenyuk@ndibk.gov.ua

The State Research Institute of Building Construtions, Kyiv, Ukraine

\title{
ESTIMATION OF INTEGRATED CHARACTERISTICS OF MATERIALS OF RAIL CONCRETE STRUCTURES BY THE METHOD OF SURFACE WAVE
}

\begin{abstract}
The basis of the method for evaluating the integral characteristics of materials of building structures is the parameters of the surface wave of the acoustic frequency range when vibrations in the construction are excited by the impulse load. Surface wave method is the complicated method for theoretical solutions, technology of measurements, methods of information procession and their further interpretation. But this complexity is justified by the advantages in obtaining integral characteristics of materials of building constructions. The integral acoustic characteristic of a planar construction (plate) is the velocity of surface wave (Rayleigh wave). The analysis and comparison of theoretical and experimental dispersion curves forms allows us to estimate the uniformity of the thickness of construction, as well as to determine this thickness. For the practical construction of experimental dispersion curves, the efficient method for measuring the phase velocity of bending waves in building constructions excited by the impulse load was developed. The problem of propagation of planar harmonic Rayleigh waves on the boundary of a rigid isotropic ideal-elastic half-space with a vacuum that can be used for determination of mechanical properties of materials of reinforced concrete plates is analyzed. The wave number, calculated voltages and displacements in the Lamb waves in each point of plate are determined. To construct the dispersion curves, the mathematical package Mathcad 13 was used. The construction of the dispersion curves takes place in three stages. The velocity of the Rayleigh surface wave is determined from the bicubic equation for the given values of the velocities of the longitudinal and transverse wave. A sequence of values of the variable $x$ is chosen, for which the corresponding equations are solved in accordance to the phase velocity $c$. The dispersion curve based on the values of the phase velocity $c$ is constructed. It is shown that the value of Rayleigh wave velocities has a nonlinear relationship with the mechanical properties of plate materials. At the rate of decline of the dispersion curves it is possible to estimate the thickness of the reinforced concrete plates. The Poisson coefficient and the density of concrete practically do not affect the character of the dispersion curves. If some of input parameters are unknown during the numerical simulation of the real plate, you can consider them to be equal to their average statistical values. In this case the maximal deviation of both the velocity of the Rayleigh waves and other points of the dispersion curve does not exceed $4 \%$.
\end{abstract}

Key words: non-destructive testing; Rayleigh waves; Lamb waves; dispersion curve; integral characteristics

(c) A.Ye. Vusatiuk, G.G. Fareniuk, 2018 


\title{
А.С. Вусатюк, Г.Г. Фаренюк
}

ДП «Науково-дослідний інститут будівельних конструкцій», Київ, Україна

\section{ОЦНКА ІНТЕГРАЛЬНИХ ХАРАКТЕРИСТИК МАТЕРІАЛІВ ЗАЛІЗОБЕТОННИХ КОНСТРУКЦІЙ МЕТОДОМ ПОВЕРХНЕВОЇ ХВИЛІ}

\begin{abstract}
Анотація. Основою методу оцінки інтегральних характеристик матеріалів будівельних конструкцій є параметри поверхневої хвилі акустичного діапазону частот при збудженні коливань в конструкції імпульсним навантаженням. Метод поверхневої хвилі є складним методом за теоретичними ріменнями, технікою вимірювань, способами обробки інформачії, подальшою ії інтерпретацією. Але така складність виправдана перевагами в отриманні інтегральних характеристик матеріалів будівельних конструкцій. Інтегральною акустичною характеристикою пласкої конструкиї (плити) $\epsilon$ швидкість поверхневої хвилі (хвилі Релея). Аналіз та порівняння форм теоретичних $i$ експериментальних дисперсійних кривих дозволяє оцінити однорідність будівельної конструкиї по товщчині, а також визначити ирю товщину. Для практичної побудови експериментальних дисперсійних кривих розроблений ефективний метод вимірювань фазової швидкості при імпульсному збудженні згинальних хвиль у будівельних конструкиіях. Проаналізовано задачу розповсюдження пласкої гармонічної хвилі Релея на границі твердого ізотропного ідеально пружного півпростору з вакуумом, що може бути використана для визначення механічних властивостей матеріалів залізобетонних плит. Визначено хвильове число і розраховані напруження $i$ зміщення у хвилях Лемба в будь-якій точиі плити. Для побудови дисперсійних кривих був використаний математичний пакет Mathcad 13. Побудова дисперсійних кривих проходить у три етапи: для заданих значень швидкості повздовжніх $i$ поперечних хвиль з бікубічного рівняння визначається швидкість поверхневої хвилі Релея; обирається послідовність значень змінної $x$, для яких відносно фазової швидкості с розв'язуються відповідні рівняння; за отриманими при виконанні попереднього етапу значеннями фазової швидкості с будується дисперсійна крива. Показано, щчо значення швидкості хвиль Релея має нелінійний зв'язок з механічними властивостями матеріалів плит. За ивидкістю спадання дисперсійних кривих можна оцінювати величину товщини залізобетонних плит. Коефімієнт Пуассона та щільність бетону практично не впливають на характер дисперсійних кривих. Якщо при чисельному моделюванні реальної плити деякі вхідні параметри невідомі, можна приймати їх рівними їхньому середньостатистичному значенню. Максимальне відхилення як швидкості хвиль Релея, так $і$ інших точок дисперсійної кривої в такому разі не перевищує $4 \%$.
\end{abstract}

Ключові слова: неруйнівні методи; хвилі Релея; хвилі Лемба; дисперсійна крива; інтегральні характеристики

\section{Вступ}

Параметри поверхневої хвилі акустичного діапазону частот при збудженні конструкції імпульсним навантаженням є основою запропонованого методу. В [1] цей метод розглядається як метод поверхневої хвилі (МПХ). MПХ є складним методом за теоретичними рішеннями, технікою вимірювань, способами обробки інформації, подальшою іiі інтерпретацією. Але така 
складність виправдана перевагами в отриманні інтегральних характеристик матеріалів будівельних конструкцій. Значний внесок у розвиток МПХ і його практичне застосування зробили спеціалісти НДЦ 26 ЦНДІ (м. СанктПетербург) [2].

Інтегральною акустичною характеристикою пласкої конструкції (плити) є швидкість поверхневої хвилі (хвилі Релея). ІІї визначають шляхом екстраполяції дисперсійної кривої в область коротких довжин хвиль. Отримані дані швидкості хвилі Релея дають змогу (при відомих значеннях щільності $\rho$ та коефіцієнта Пуассона $\mu$ ) розрахувати динамічні пружні характеристики матеріалу конструкції: модуль пружності та модуль зсуву. Аналіз та порівняння форм теоретичних i експериментальних дисперсійних кривих дозволяє оцінити однорідність конструкції по товщині, а також визначити цю товщину.

Наявність дисперсії, за визначенням, означає, що форма коливань змінюється у процесі їх розповсюдження. Дисперсія виникає тоді, коли швидкість розповсюдження хвилі залежить від частоти (тобто хвилі різних частот розповсюджуються з різною швидкістю), а під дисперсійною кривою зазвичай розуміють графік залежності фазової швидкості коливань від частоти коливань [3]. Проте для наших задач зручно будувати дисперсійну криву як залежність фазової швидкості від довжини хвилі або від відношення довжини хвилі до товщини плити.

Процедури побудови теоретичних дисперсійних кривих, в основу яких покладено отримання залежності між фазовою швидкістю $c$ і відношенням $\frac{\lambda}{H}$, де $\lambda$ - довжина хвилі, а $H$ - товщина плити, розглянуті рядом авторів [1-8]. Але для практичного застосування при вирішенні конкретних задач потребувалось проведення теоретичних досліджень. У статті для побудови експериментальних дисперсійних кривих розроблений ефективний метод вимірювань фазової швидкості при імпульсному збудженні у конструкціях згинальних хвиль $[2,8]$.

\section{Хвилі Релея}

Хвилями Релея називають пружні коливання, що розповсюджуються поблизу вільної границі твердого тіла та затухають з глибиною [6]. Розглянемо пласку гармонічну хвилю Релея на границі твердого ізотропного ідеально пружного півпростору з вакуумом. Нехай півпростір займає область $z>0$, а напрям розповсюдження хвилі збігається 3 віссю $x$. Введемо для області, зайнятої півпростором, скалярний $\varphi$ і векторний $\psi$ потенціали зміщень, так що вектор зміщень частинок $v$ запишеться у вигляді

$$
v=\operatorname{grad} \varphi+\operatorname{rot} \psi
$$

Оскільки хвиля пласка і рух не залежить від координати $y$, у векторного потенціалу буде відмінна від нуля лише компонента по осі $y$; цю компоненту позначимо просто через $\psi$. Потенціали $\varphi$ та $\psi$ називаються відповідно потенціалами повздовжніх і зсувних хвиль та задовольняють (для гармонічних процесів) хвильовим рівнянням Гельмгольця 2-го роду: 


$$
\frac{\partial^{2} \phi}{\partial x^{2}}+\frac{\partial^{2} \phi}{\partial z^{2}}+k_{L}^{2} \phi=0 \quad \frac{\partial^{2} \psi}{\partial x^{2}}+\frac{\partial^{2} \psi}{\partial z^{2}}+k_{T}^{2} \psi=0
$$

де: $k_{L}=\omega \sqrt{\frac{\rho}{\lambda+2 \mu}}, k_{T}=\omega \sqrt{\frac{\rho}{\mu}}-$ хвильові числа відповідно повздовжніх та поперечних хвиль; $\omega$ - кругова частота; $\lambda$ і $\mu$ - пружні постійні Ламе; $\rho-$ щільність середовища. Вирази для $\varphi$ та $\psi$ приймають вигляд:

$$
\phi=A e^{-q z} e^{t(k x-\omega t)} \quad \psi=B e^{-s z} e^{t(k x-\omega t)},
$$

де: $q^{2}=k^{2}-k_{L}^{2} ; s^{2}=k^{2}-k_{T}^{2} ; A$ та $B$ - довільні постійні.

Умови задачі потребують, щоб напруги $\sigma_{z z}$ та $\sigma_{x z}$ дорівнювали нулю на границі півпростору (площина $z=0$ ). Підставляючи вирази для $\varphi$ та $\psi$ у ці умови, отримаємо співвідношення, що пов'язують $A, B$ та хвильове число $k$. У результаті для $\varphi$ та $\psi$ отримуємо

$$
\phi=-A e^{i(k x-\omega t)-q z} \quad \psi=i A \frac{2 k q}{k^{2}+s^{2}} e^{i(k x-\omega t)-s z}
$$

Рівняння для визначення $k$ (характеристичне рівняння) буде мати вигляд

$$
4 k^{2} q s-\left(k^{2}+s^{2}\right)^{2}=0
$$

Після простих перетворень воно зводиться до форми

$$
\eta^{6}-8 \eta^{4}+8\left(3-2 \xi^{2}\right) \eta^{2}-16\left(1-\xi^{2}\right)=0
$$

де: $\eta=\frac{k_{T}}{k}=\frac{c}{c_{T}} ; \xi=\frac{k_{L}}{k_{T}}=\frac{c_{T}}{c_{L}}\left(c_{L}, c_{T}-\right.$ фазові швидкості повздовжніх і поперечних хвиль). Це рівняння називається рівнянням Релея. Воно має шість коренів, значення яких залежить тільки від коефіцієнта Пуассона $\mu$ даного пружного середовища. Хвилі Релея відповідає корінь $\eta_{R}$, що знаходиться між нулем та одиницею. Для будь-якого значення $\mu$, що відповідає реальному середовищу $0 \leq \mu \leq 0,5$, рівняння (5) має один і тільки один корінь. Цей факт підтверджує справедливість прийнятої гіпотези та доводить існування хвилі Релея на вільній границі пружного півпростору.

\section{Хвилі Лемба}

Хвилями Лемба називаються пружні коливання, що розповсюджуються у твердій пластині з вільними границями, у яких має місце зміщення, як у 
напрямку розповсюдження хвилі, так і ортогонально до площини пластини $[6,7]$. Розглянемо пласку гармонічну хвилю Лемба, що розповсюджується у пластині товщиною $2 d$ у додатному напрямку осі $x$. Введемо для області, зайнятої пластиною, скалярний $\varphi$ і векторний $\psi$ потенціали зміщень, що пов'язані з вектором зміщень співвідношенням (1). Як і в пласкій хвилі Релея, у векторного потенціалу буде відмінна від нуля тільки компонента по осі $y$, яку ми також позначимо просто $\psi$. Потенціали $\varphi$ та $\psi$, що описують відповідно повздовжні та поперечні хвилі, повинні задовольняти хвильовим рівнянням (2). Представимо $\varphi$ та $\psi$ у наступній формі

$$
\phi=A_{s} \operatorname{ch} q z e^{i k x}+B_{a} \operatorname{sh} q z e^{i k x} \quad \psi=D_{s} \operatorname{sh} s z e^{i k x}+C_{a} \operatorname{ch} s z e^{i k x}
$$

де: $A_{s}, B_{a}, C_{a}, D_{s}$ - довільні постійні; $k$ - хвильове число хвиль Лемба;

$$
q=\sqrt{k^{2}-k_{L}^{2}} ; s=\sqrt{k^{2}-k_{T}^{2}} .
$$

Неважко побачити, що вирази (6) задовольняють хвильовим рівнянням (2). Прирівнюючи напруги до нуля, отримуємо наступну систему лінійних однорідних рівнянь для знаходження амплітуд $A_{s}, B_{a}, C_{a}, D_{s}$ :

$$
\begin{aligned}
& \left(k^{2}+s^{2}\right) \operatorname{ch} q d A_{s}+\left(k^{2}+s^{2}\right) \operatorname{sh} q d B_{a}+2 i k s s h s d C_{a}+2 i k s c h s d D_{s}=0 \\
& \left(k^{2}+s^{2}\right) \operatorname{ch} q d A_{s}-\left(k^{2}+s^{2}\right) \operatorname{sh} q d B_{a}-2 i k s s h s d C_{a}+2 i k s c h s d D_{s}=0 \\
& 2 i k q \operatorname{sh} q d A_{s}+2 i k q c h q d B_{a}-\left(k^{2}+s^{2}\right) \operatorname{ch} s d C_{a}-\left(k^{2}+s^{2}\right) s h s d D_{s}=0 \\
& -2 i k q s h q d A_{s}+2 i k q c h q d B_{a}-\left(k^{2}+s^{2}\right) \operatorname{ch} s d C_{a}+\left(k^{2}+s^{2}\right) s h s d D_{s}=0
\end{aligned}
$$

Неважко помітити, що записана система задовольняється, якщо задовольняються дві підсистеми:

$$
\begin{aligned}
& \left(k^{2}+s^{2}\right) \operatorname{ch} q d A_{s}+2 i k s c h s d D_{s}=0 \quad 2 i k q \operatorname{sh} q d A_{s}-\left(k^{2}+s^{2}\right) s h s d D_{s}=0, \\
& \left(k^{2}+s^{2}\right) \operatorname{sh} q d B_{a}+2 i k s s h s d C_{a}=0 \quad 2 i k q c h q d B_{a}-\left(k^{2}+s^{2}\right) \operatorname{ch} s d C_{a}=0 .
\end{aligned}
$$

Підсистеми мають нетривіальні розв'язки лише тоді, коли їхні детермінанти дорівнюють нулю. Ми приходимо до двох характеристичних рівнянь, що визначають власні значення хвильового числа $k$ :

$$
\begin{aligned}
& \left(k^{2}+s^{2}\right)^{2} \text { ch qd sh } s d-4 k^{2} q s \text { sh } q d \text { ch } s d=0 \\
& \left(k^{2}+s^{2}\right)^{2} \operatorname{sh} q d \operatorname{ch} s d-4 k^{2} q s \text { ch } q d \text { sh } s d=0
\end{aligned}
$$

Використавши ці рівняння, отримаємо з підсистеми (5) вираз для $D_{s}$ через $A_{s}$, а $з$ підсистеми (8) вираз для $C_{a}$ через $B_{a}$. Отримаємо формули для шуканих потенціалів: 
$\phi=A_{s} \operatorname{ch} q_{s} z e^{i k_{s} x}+B_{a} \operatorname{sh} q_{a} z e^{i k_{a} x} \psi=\frac{2 i k_{s} q_{s} s h q_{s} d}{\left(k_{s}^{2}+s_{s}^{2}\right) \operatorname{sh} s_{s} d} A_{s} \operatorname{sh} s_{s} z e^{i k_{s} x}+$ $+\frac{2 i k_{a} q_{a} c h q_{a} d}{\left(k_{a}^{2}+s_{a}^{2}\right) c h s_{a} d} B_{a} \operatorname{chs}_{a} z e^{i k_{a} x}$

де: $k_{s}$ - значення $k$, що задовольняє рівнянню (7); $k_{a}-$ значення $k$, що задовольняє рівнянню (8):

$$
q_{s, a}=\sqrt{k_{s, a}^{2}-k_{L}^{2}}, s_{s, a}=\sqrt{k_{s, a}^{2}-k_{T}^{2}} .
$$

3 формул (11) можемо розрахувати компоненти зміщень $U$ та $W$ :

$$
\begin{gathered}
U=U_{s}+U_{a} \quad W=W_{s}+W_{a} \\
U_{s}=A k_{s}\left(\frac{c h q_{s} z}{s h q_{s} d}-\frac{2 q_{s} s_{s}}{k_{s}^{2}+s_{s}^{2}} \cdot \frac{c h s_{s} z}{s h s_{s} d}\right) e^{i\left(k_{s} x-\omega t-\frac{\pi}{2}\right)} \\
W_{s}=-A q_{s}\left(\frac{s h q_{s} z}{s h q_{s} d}-\frac{2 k_{s}^{2}}{k_{s}^{2}+s_{s}^{2}} \cdot \frac{s h s_{s} z}{s h s_{s} d}\right) e^{i\left(k_{s} x-\omega t\right)} ; \\
U_{a}=B k_{a}\left(\frac{s h q_{a} Z}{c h q_{a} d}-\frac{2 q_{a} s_{a}}{k_{a}^{2}+s_{a}^{2}} \cdot \frac{s}{c h s_{a} z}\right) e^{i\left(k_{a} x-\omega t-\frac{\pi}{2}\right)} \\
W_{a}=-B q_{a}\left(\frac{c h q_{a} z}{c h q_{a} d}-\frac{2 k_{a}^{2}}{k_{a}^{2}+s_{a}^{2}} \cdot \frac{c h s_{a} z}{c h s_{a} d}\right) e^{i\left(k_{a} x-\omega t\right)},
\end{gathered}
$$

де $A$ та $B$ - нові довільні постійні.

Вирази (11-14), а також рівняння (9), (10) описують дві групи хвиль, кожна 3 яких задовольняє хвильовим рівнянням руху та граничним умовам, тобто може розповсюджуватися у пластині незалежно одна від одної. Аналізуючи вирази (13) та (14), можемо зробити наступні висновки:

- Перша група хвиль, що позначена індексом $s$, описує хвилі, в яких рух відбувається симетрично відносно площини $z=0$ (тобто у верхній та нижній половинках пластини зміщення $U$ має однакові знаки, а зміщення $W-$ протилежні). Хвилі першої групи називають симетричними хвилями Лемба.

- Друга група, що позначена індексом $a$, описує хвилі, в яких переміщення відбувається антисиметрично відносно площини $z=0$ (тобто у верхній та нижній половинках пластини зміщення $U$ має протилежні знаки, а зміщення $W-$ однакові). Хвилі другої групи називають антисиметричними (згинальними) хвилями Лемба.

\section{Дисперсійні криві}

Фазова швидкість $c$ є основною характеристикою хвилі Лемба. Знаючи їі, ми можемо визначити хвильове число і розрахувати напругу і зміщення у хвилі Лемба в будь-якій точці плити. Фазова швидкість знаходиться шляхом чисельного розв'язку характеристичних рівнянь (9), (10), які доцільно переписати у наступній формі [6]: 
для симетричних хвиль:

$$
\frac{\operatorname{tg} \sqrt{1-\zeta^{2}} \bar{d}}{\operatorname{tg} \sqrt{\xi^{2}-\zeta^{2}} \bar{d}}=-\frac{4 \zeta^{2} \sqrt{1-\zeta^{2}} \sqrt{\xi^{2}-\zeta^{2}}}{\left(2 \zeta^{2}-1\right)^{2}},
$$

для антисиметричних (згинальних) хвиль:

$$
\frac{\operatorname{tg} \sqrt{1-\zeta^{2}} \bar{d}}{\operatorname{tg} \sqrt{\xi^{2}-\zeta^{2}} \bar{d}}=-\frac{\left(2 \zeta^{2}-1\right)^{2}}{4 \zeta^{2} \sqrt{1-\zeta^{2}} \sqrt{\xi^{2}-\zeta^{2}}} .
$$

Тут: $\bar{d}=k_{T} d ; \zeta^{2}=\frac{c_{T}^{2}}{c^{2}} ; \xi^{2}=\frac{c_{T}^{2}}{c_{L}^{2}}, c_{L}-$ швидкість повздовжніх хвиль; $c_{T}-$ швидкість поперечних хвиль; $k_{T}$ - номер моди коливання поперечних хвиль; $d$ - половина товщини плити.

Для побудови експериментальних дисперсійних кривих розроблений ефективний метод вимірювань фазової швидкості при імпульсному збудженні у конструкціях згинальних хвиль [2, 8], тому теоретичні дисперсійні хвилі також будуватимемо для згинальних хвиль, за рівнянням (16). Для побудови необхідно отримати залежність між фазовою швидкістю згинальних коливань $c$ та відношенням $\lambda / H$, де $\lambda$ - довжина хвилі Лемба, $H$ - товщина плити. Для цього приведемо рівняння для обчислення фазової швидкості антисиметричних хвиль до трансцендентного рівняння 3 двома невідомими. Використовуючи співвідношення між номером моди коливань і довжиною хвилі: $k=2 \pi / \lambda$, а також той факт, що довжина хвилі є добутком фазової швидкості цієї хвилі на один період коливань, ми можемо виконати наступні перетворення:

$$
\bar{d}=k_{T} d=\frac{2 \pi}{\lambda_{T}} \cdot \frac{H}{2}=\frac{\pi H}{c_{T} T}=\frac{\pi H}{\lambda} \cdot \frac{c}{c_{T}} .
$$

Тепер підставимо замість $\xi^{2}$ і $\zeta^{2}$ відповідні відношення квадратів швидкостей і перетворимо ліву частину рівняння (16):

$$
\frac{\operatorname{tg} \sqrt{1-\zeta^{2}} \bar{d}}{\operatorname{tg} \sqrt{\xi^{2}-\zeta^{2}} \bar{d}}=\frac{\operatorname{tg} \frac{\pi H}{\lambda} \frac{c}{c_{T}} \sqrt{1-\frac{c_{T}^{2}}{c^{2}}}}{\operatorname{tg} \frac{\pi H}{\lambda} \frac{c}{c_{T}} \sqrt{\frac{c_{T}^{2}}{c_{L}^{2}}-\frac{c_{T}^{2}}{c^{2}}}}=\frac{\operatorname{tg} \frac{\pi}{(\lambda / H)} \sqrt{\frac{c^{2}}{c_{T}^{2}}-1}}{\operatorname{tg} \frac{\pi}{(\lambda / H)} \sqrt{\frac{c^{2}}{c_{L}^{2}}-1}} .
$$

Зробимо припущення, що має місце нерівність $c<c_{R}$, де $c_{R}$ - швидкість хвилі Релея. Припустимо, що для хвильового числа хвилі Релея $k_{R}^{2}>k_{T}^{2}>k_{L}^{2}$. Так як $\frac{k_{T}}{k_{R}}=\frac{c_{R}}{c_{T}}, \frac{k_{L}}{k_{T}}=\frac{c_{T}}{c_{L}}$, враховуючи зроблене припущення, отримуємо 
$\frac{c^{2}}{c_{T}^{2}}-1<\frac{c_{R}^{2}}{c_{T}^{2}}-1<0$ i $\frac{c^{2}}{c_{L}^{2}}-1<\frac{c_{R}^{2}}{c_{L}^{2}}-1<0$. Таким чином, підкорінні вирази набувають від'ємних значень, а тангенс береться виключно від уявного виразу. Ліва частина рівняння (16) для обчислення фазової швидкості згинальних хвиль $€$ функцією двох змінних - фазової швидкості згинальних хвиль $c$ і відношення $\lambda / H$, а права - функцією, що залежить тільки від фазової швидкості $c$.

Введемо заміну: $\lambda / H=x$. Рівняння для обчислення фазової швидкості згинальних хвиль тепер запишемо у вигляді трансцендентного рівняння 3 двома невідомими: фазовою швидкістю $c$ i $x$ - відношенням довжини хвилі до товщини плити:

$$
\frac{\operatorname{th} \frac{\pi}{x} \sqrt{1-\frac{c^{2}}{c_{T}^{2}}}}{\operatorname{th} \frac{\pi}{x} \sqrt{1-\frac{c^{2}}{c_{L}^{2}}}}=\frac{\left(2-\frac{c^{2}}{c_{T}^{2}}\right)^{2}}{4 \sqrt{1-\frac{c^{2}}{c_{T}^{2}}} \sqrt{1-\frac{c^{2}}{c_{L}^{2}}}} .
$$

Визначимо фазову швидкість згинальних хвиль для граничних значень довжини хвилі: $\lambda \rightarrow 0$ і $\lambda \rightarrow \infty$. Доведемо, що коли довжина хвилі прямує до нуля, швидкість згинальних хвиль прямує до швидкості хвилі Релея. При $\lambda \rightarrow 0$ рівняння (18) приймає вигляд:

$$
\frac{1}{1}=\frac{\left(2-\frac{c^{2}}{c_{T}^{2}}\right)^{2}}{4 \sqrt{1-\frac{c^{2}}{c_{T}^{2}} \sqrt{1-\frac{c^{2}}{c_{L}^{2}}}}}, \text { або } \quad 4 \sqrt{1-\frac{c^{2}}{c_{T}^{2}}} \sqrt{1-\frac{c^{2}}{c_{L}^{2}}}=\left(2-\frac{c^{2}}{c_{T}^{2}}\right)^{2}
$$

Піднесемо обидві частини отриманого рівняння в квадрат і, виконуючи над ним подальші перетворення, приводимо його до бікубічного рівняння, яке співпадає з рівнянням хвиль Релея (5).

Тепер розглянемо випадок $\lambda \rightarrow \infty$. Обернено пропорційні довжині хвилі вирази прямують до нуля. Оскільки $\lim _{z \rightarrow 0}\left(\frac{\operatorname{th}(z)}{z}\right)=1$, рівняння (18) набуває вигляду:

$$
4\left(1-\frac{c^{2}}{c_{T}^{2}}\right)=\left(2-\frac{c^{2}}{c_{T}^{2}}\right)^{2}
$$

звідки $c=0$. Таким чином, при нескінченно малих значеннях довжини хвилі фазова швидкість згинальних хвиль прямує до швидкості хвиль Релея та знаходиться з відповідного бікубічного рівняння, а при нескінченно великих прямує до нуля. Що стосується прийнятого припущення, згідно з яким $c<c_{R}$, можна довести існування розв'язку рівняння (18) для будь-якого значення $0<x<\infty$, що задовольняє умову $c<c_{R}$. Для побудови дисперсійних кривих 
був використаний математичний пакет Mathcad 13. У його програмному середовищі була реалізована процедура розв'язання отриманого рівняння для послідовності значень змінної $x$, що дозволяє виконати побудову графіків поточково.

Побудова дисперсійних кривих проходить у три етапи:

1. Для заданих значень швидкості повздовжніх i поперечних хвиль 3 бікубічного рівняння (5) визначається швидкість поверхневої хвилі Релея $c_{R}$.

2. Обирається послідовність значень змінної $x$, для яких відносно фазової швидкості $c$ розв'язуються рівняння (18).

3. За отриманими при виконанні попереднього етапу значеннями фазової швидкості $c$ будується дисперсійна крива - графік залежності між величинами $c$ та $\lambda$ або між величинами $c$ та $x=\lambda / H$.

\section{Приклад побудови дисперсійної кривої}

На рис. 1 зображено дисперсійні криві для згинальних хвиль у плитах, зроблених із різних матеріалів: бетону (крива С1), силікатної цегли (крива С2) та керамічної цегли (крива С3). Для побудови кривих бралися середні значення механічних характеристик матеріалів. Для бетонної плити: швидкість повздовжніх коливань - $4150 \mathrm{~m} / \mathrm{c}$, коефіцієнт Пуассона 0,2; для плити із силікатної цегли: швидкість повздовжніх коливань - 3000 м/с, коефіцієнт Пуассона 0,28; для плити з керамічної цегли: швидкість повздовжніх коливань - 1570 м/с, швидкість поперечних коливань - 980 м/с. Товщина плити - 0,52 м.

Порівняємо загальний вигляд кривих С1, C2 та С3. Усі дисперсійні криві мають приблизно однакову форму, але значно різняться висотою розташування. Форма дисперсійних кривих характерна; таку ж форму мають графіки функцій виду $f(x)=\frac{t h(\alpha / x)}{t h(\beta / x)}-C$ при $\alpha<\beta$. Різниця у висоті розташування кривих $\mathrm{C} 1, \mathrm{C} 2$ та $\mathrm{C} 3$ відображає різницю у фазовій швидкості згинальних хвиль та швидкості хвиль Релея. Розрахована швидкість хвиль Релея плит 3 матеріалів 3 даними механічними характеристиками становить 2315,2 м/с для бетонної плити, 1532,7 м/с для плити із силікатної цегли та 889,5 м/с для плити з керамічної цегли. Таким чином, значення швидкості хвиль Релея має нелінійний зв'язок з механічними властивостями матеріалів плит.

Розрахунки також були проведені для наступних трьох випадків плит, зроблених з одного й того ж матеріалу - бетону, але різної товщини: $0,15,0,45$, 0,8 та 1,5 м; з різними значеннями коефіцієнта Пуассона; різної щільності.

\section{Висновки}

1. Значення швидкості хвиль Релея має нелінійний зв'язок з механічними властивостями матеріалів плит та може бути використане для їхньої оцінки.

2. За швидкістю спадання дисперсійних кривих можна оцінювати величину товщини плит.

3. Коефіцієнт Пуассона та щільність бетону практично не впливають на характер дисперсійних кривих. Якщо при моделюванні реальної плити ці параметри невідомі, можна приймати їх рівними їхньому середньостатистичному значенню, так як максимальне відхилення як швидкості хвиль Релея, так і інших точок дисперсійної кривої при цьому не перевищує 4\%. 


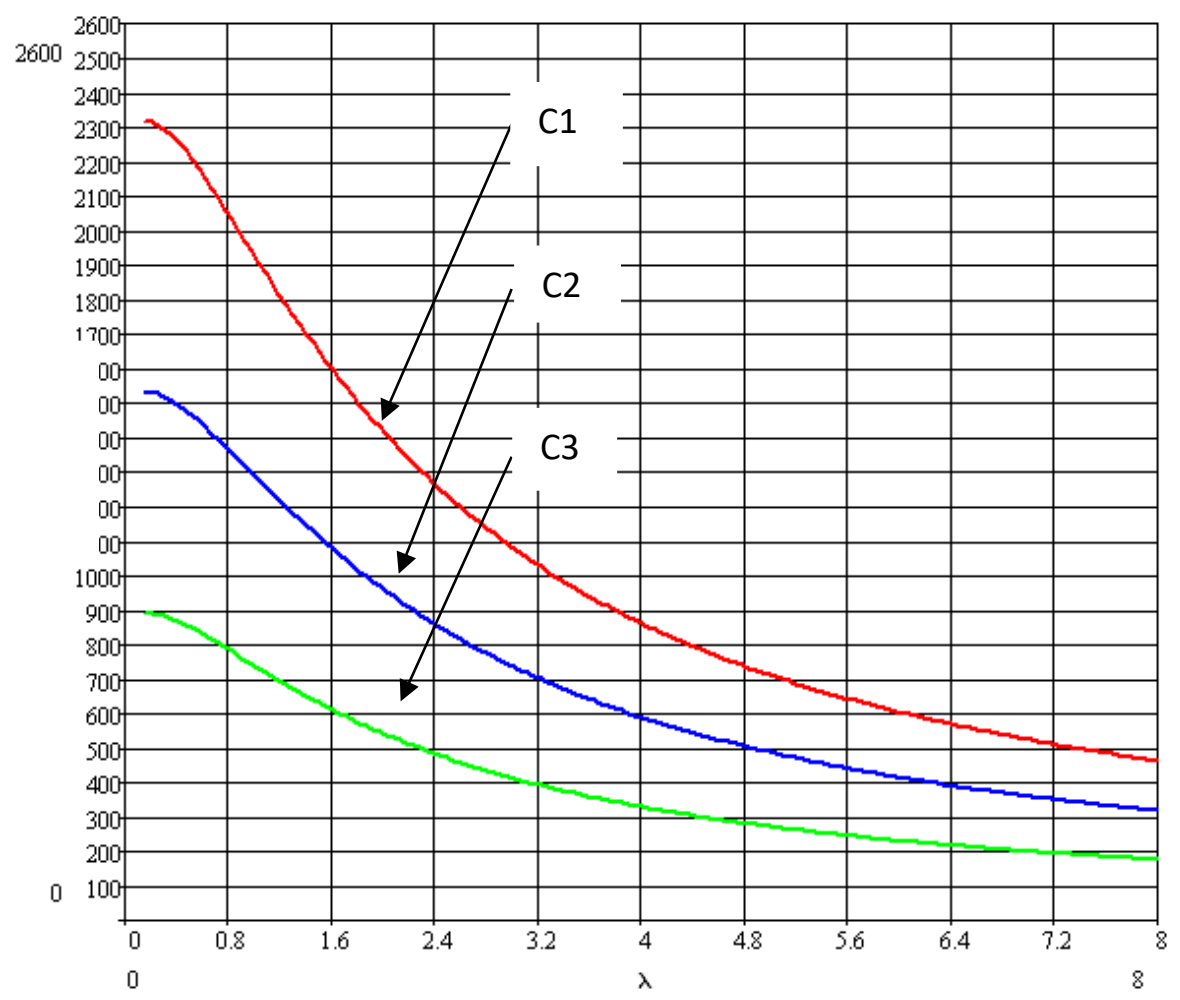

Рис. 1 - Дисперсійні криві згинальних хвиль у плитах, зроблених із різних матеріалів: бетону (крива С1), силікатної цегли (крива С2) та керамічної цегли (крива С3)

\section{СПИСОК ЛІТЕРАТУРИ}

1. Джонс Р., Фэкэоару И. Неразрушающие методы испытаний бетонов Пер. с румынск. - М.: Стройиздат, 1974. - 292 с.

2. Современные методы технической диагностики строительных конструкций, зданий и сооружений / [Заренков В.А., Захаров И.Д., Савин С.Н., Шнитковский А.Ф.; ред. С.Н. Савина]. - СПб.: РДК-принт, 2000. - 128 с.

3. Стрелков С.П. Введение в теорию колебаний. - М.: Наука, 1964. - 442 с.

4. Гарифулин Д.М., Есенина Н.А., Ситников И.В. Применение инструментальных обследований для оценки фактического состояния строительных конструкций зданий атомных станций // Сейсмостойкое строительство. - №6, 1999. - С. 15-18.

5. Алешин Н.Н. Элекстросейсмоакустические методы обследования зданий. - М.: Стройиздат, 1982. - $158 \mathrm{c}$.

6. Викторов И.А. Физические основы применения ультразвуковых волн Рэлея и Лэмба в технике. М.: Наука, 1966. - 168 с.

7. Achenbach J.D. Wave propagation in elastic solids. Amsterdam: North-Holland Published Company, 1973.

8. Rose, J. L. Ultrasonic Waves in Solid Media. New York, NY, Cambridge University Press, 1999.

Стаття надійшла до редакиії 04.12.2018 


\section{REFERENCES (TRANSLATED AND TRANSLITERATED)}

1. Facaeoaru. I., \& Jones, R. (1974). Non-destructive testing of concrete. Moscow: Stroiizdat (in Russian).

2. Zarenkov, V. A., Zaharov, I. D., Savin, S. N., \& Shnitkovskij, A. F. (2000). Sovremennye metody tehnicheskoj diagnostiki stroitel'nyh konstrukcij, zdanij i sooruzhenij (S. N. Savin, Ed.). SPb: RDK-print (in Russian).

3. Strelkov, S. P. (1964). Vvedenie v teoriju kolebanij. Moscow: Nauka (in Russian).

4. Garifulin, D. M., Esenina, N. A., \& Sitnikov, I. V. (1999). Primenenie instrumental'nyh obsledovanij dlja ocenki fakticheskogo sostojanija stroitel'nyh konstrukcij zdanij atomnyh stancij. Sejsmostojkoe stroitel'stvo (6) 15-18 (in Russian).

5. Aleshin, N. N. (1982). Jelekstrosejsmoakusticheskie metody obsledovanija zdanij. Moscow: Stroiizdat (in Russian).

6. Viktorov, I. A. (1966). Fizicheskie osnovy primenenija ul'trazvukovyh voln Rjeleja $i$ Ljemba v tehnike. Moscow: Nauka (in Russian).

7. Achenbach, J. D. (1973). Wave propagation in elastic solids. Amsterdam: North-Holland Published Company (in English).

8. Rose, J. L. (1999). Waves in Solid Media. New York: Cambridge University Press (in English).

Text of the article was accepted by Editorial Team 04.12.2018

\section{Вусатюк Андрій Свгенійович}

здобувач наукового ступеня кандидата технічних наук ДП «Науково-дослідний інститут будівельних конструкцій»

Адреса робоча: 03037 Україна, вул. Преображенська, 5/2

ORCID ID 0000-0002-3096-3188 e-mail: avusatiuk@gmail.com

\section{Фаренюк Геннадій Григорович}

доктор технічних наук, директор ДП «Науково-дослідний інститут будівельних конструкцій»

Адреса робоча: 03037 Україна, вул. Преображенська, 5/2

ORCID 0000-0002-5703-3976 e-mail: farenyuk@ndibk.gov.ua 